\title{
Morphological abnormalities in mitochondria of the skin of patients with sporadic amyotrophic lateral sclerosis
}

\author{
Alteraciones morfológicas en las mitocondrias en la piel de enfermos con esclerosis \\ lateral amiotrófica esporádica
}

Gabriel E. Rodriguez ${ }^{1,2}$, Deniselle M. Claudia González 3,4 , Gisella M. Gargiulo Monachelli1,4, Juan J. López

Costa ${ }^{5}$, Alejandro F. de Nicola ${ }^{3,4}$, Roberto E. P. Sica ${ }^{2}$

\begin{abstract}
Objectives: Mitochondrial dysfunction has been reported in the central nervous system, hepatocytes and peripheral blood lymphocytes from patients with sporadic amyotrophic lateral sclerosis (SALS). However, the status of skin mitochondria has not been reported, in spite of the fact that SALS patients present skin abnormalities. The objective of the present study was to compare mitochondrial ultrastructural parameters in keratinocytes from patients with SALS and healthy controls. Methods: Our study was based on the analysis of 112 skin mitochondria from 5 SALS patients and 99 organelles from 4 control subjects by electron microscopy. Results: Computerized image analysis showed that mitochondrial major axis length, area and perimeter of the organelle were significantly smaller in SALS respect of healthy control subjects. Morphologically, SALS mitochondria presented cristolysis and breakage of the outer membrane. Conclusions: Mitochondrial dysfunction in the skin may possibly reflect changes occurring in mitochondria of the central nervous system. The analysis of mitochondrial morphology in this tissue may be of value to follow disease progression and, eventually, the effectiveness of current therapies for SALS.
\end{abstract}

Key words: amyotrophic lateral sclerosis, electron microscopy, keratinocytes, mitochondria.

\section{RESUMEN}

Objetivos: Existen alteraciones en la función mitocondrial en el sistema nervioso central, en hepatocitos y en linfocitos de sangre periférica en SALS. Aunque, no se ha estudiado si existen cambios estructurales en las mitocondrias de la piel. Nuestro objetivo fue comparar la ultraestructura de mitocondrias en queratinocitos de enfermos con SALS con la de controles sanos. Método: Fueron analizadas en el microscopio electrónico 112 mitocondrias dérmicas de 5 pacientes y 99 provenientes de 4 controles. Resultados: EL análisis computarizado mostró que el eje mayor mitocondrial, el área y el perímetro de las organelas fueran significativamente menor que en controles. Morfológicamente, las mitocondrias de SALS presentaron cristólisis y ruptura de la membrana externa. Conclusión: La alteración mitocondrial en la piel posiblemente refleje cambios que también ocurran en las mitocondrias neuronales. Este análisis morfológico de las mitocondrias podría tener valor en el seguimiento de la enfermedad y eventualmente en la evaluación de la efectividad de futuras terapias.

Palabras-Clave: esclerosis amiotrófica lateral, microscopía electrónica, queratinocitos, mitocondria.

Amyotrophic lateral sclerosis (ALS) is a fatal neurodegenerative disease that compromises motor neurons of the spinal cord and brainstem. About 10 to 20\% of ALS cases belong to the familial form (FALS); 2 to $5 \%$ of them present a mutation in the superoxide dismutase type I (SOD1) gene. The largest majority of patients belong to the sporadic form
(SALS) of unknown etiology. Multiple factors have been held responsible for motor neuron degeneration, including glutamate excitotoxicity, increased generation of reactive oxygen species (ROS), abnormal mitochondrial function, altered calcium homeostasis, deposits of cytoplasmic clusters of protein aggregates, proteasomal disability, impaired

\footnotetext{
${ }^{1}$ Neurology Department, Hospital Ramos Mejía, Buenos Aires, Argentina;

${ }^{2}$ Department of Science and Technology, School of Medicine, University of Buenos Aires (UBA), Buenos Aires, Argentina;

${ }^{3}$ Department of Human Biochemistry, School of Medicine, UBA, Buenos Aires, Argentina,

4Laboratory of Neuroendocrine Biochemistry, Institute of Medicine and Experimental Biology - CONICET, Buenos Aires, Argentina;

${ }^{5}$ Institute of Cell Biology and Neuroscience "Prof. E. de Robertis", School of Medicine, UBA, Buenos Aires, Argentina.

Correspondence: Gabriel E. Rodríguez; Neurology Department; Hospital Ramos JM Ramos Mejía; Urquiza 609; CP: 1221 Buenos Aires - Argentina; Email:gerodrig@intramed.net

Support: The University of Buenos Aires (UBACyT M029), Fiorini Foundation and the National Research Council of Argentina (CONICET, PIP).

Conflict of interest: There is no conflict of interest to declare.

Received 09 February 2011; Received in final form 18 August 2011; Accepted 25 August 2011
} 
axoplasmic transport, changes of cytoskeletal architecture and inflammation ${ }^{1}$.

Participation of oxidative stress in SALS is supported by the increased content of oxidative markers in biological fluids $^{2-4}$. Pathological overproduction of ROS could arise from either increased production or decreased activity of antioxidant scavengers. In pathological situations, mitochondria have been implicated in generation of ROS, calcium-mediated excitotoxicity and intrinsic apoptotic pathways ${ }^{5}$.

There is substantial evidence for mitochondrial dysfunction in SALS, supported by morphological, molecular and functional observations in human patients, transgenic mice overexpressing mutant SOD1 and the Wobbler mouse mutant. Afifi and colleagues ${ }^{6}$ first reported abnormal mitochondrial morphology in the atrophic muscles of SALS patients and, subsequently, mitochondrial abnormalities have been reported in the central nervous system ${ }^{7-10}$, liver cells ${ }^{11}$ and peripheral blood lymphocytes ${ }^{12}$ of SALS patients. Muscle biopsies in SALS have shown increased mitochondrial volume associated to increased calcium levels ${ }^{13}$; also, reduced activity of mitochondrial respiratory chain complex I and complex IV in skeletal muscle and the spinal cord have been reported ${ }^{14,15}$. Along this line, electron microscopy of motor neurons from animal models of ALS, including SOD1 transgenic and Wobbler mice, revealed prominent mitochondrial abnormalities, such as vacuolation, crystolysis, edema and rupture of outer membranes ${ }^{16-18}$.

Recent findings have greatly expanded our understanding of the mitochondria role in the pathogenesis of neurodegenerative diseases. Indeed, mitochondrial dysfunction and oxidative stress occur early in all major neurodegenerative diseases, and there is strong evidence that mitochondrial impairment aggravates disease outcome ${ }^{19}$.

In spite of the fact that SALS has been considered a disease of motor neurons, it might also compromise other organs, such as the skin. In this respect, SALS patients are resistant to the development of pressure sores (decubitus ulcers). The skin of these patients feels supple, like tanned leather, and loses elasticity. Fullmer and colleagues ${ }^{20}$ have found extensive alterations within the connective tissues of the dermis in a high percentage of SALS patients. The reported skin changes include elastosis, increased mucopolysaccharides, local areas of regenerated connective tissue and altered collagen ${ }^{21,22}$. Deposits of amorphous material consisting of hyaluronic acid have been found in skin biopsies from SALS patients, but not from controls and, interestingly, the amount of this mucopolysaccharide acid correlates with disease length ${ }^{23-25}$. Therefore, it is likely that mitochondrial abnormalities are not restricted to the central nervous system (CNS) and may appear in tissues yet unexplored. Taking into consideration this possibility, the objective of our study was to compare mitochondrial ultrastructural parameters in keratinocytes from the skin of SALS patients and healthy controls.

\section{METHODS}

We analyzed 112 mitochondria from 5 patients with the diagnosis of definite SALS, based on El Escorial (Arlie House modified) criteria ${ }^{26,27}$ and 99 from 4 healthy controls without any signs of neurological disease. We performed a skin biopsy with a punch device number 3 after local anesthesia with $3 \%$ lidocaine. Keratinocytes measured in the study were those near the basement membrane. The latter was identified morphologically by electron microscopy. The research protocol was approved by the Ethics Committee of the Ramos Mejía Hospital and informed consent was obtained in writing from each individual tested.

\section{Electron microscopy}

The biopsies were taken from the skin of the shoulder and small blocks of tissue were obtained by cutting longitudinal sections of 3-5 mm maximum thickness. Blocks were immersed immediately for $2 \mathrm{~h}$ in phosphate buffered $2.5 \%$ glutaraldehyde. After overnight washing in $0.1 \mathrm{M}$ sodium phosphate buffer, tissue blocks containing the epidermal region were postfixed in $1 \% \mathrm{OsO}_{4}$ in $0.1 \mathrm{M}$ phosphate buffer $\mathrm{pH} 7.4$ for $1 \mathrm{~h}$ and stained with $1 \%$ uranyl acetate. Afterwards, tissue blocks were dehydrated and flat-embedded in Durcupan (Fluka Chemic AG, Sweden). Semithin sections $(0.8-1 \mu \mathrm{m})$ were stained with toluidine blue for light microscopy (LM) observations. For electron microscopy (EM), ultrathin sections (60-70 nm) were obtained with a Reichert ultramicrotome (Vienna, Austria) from keratinocytes. Sections were stained with lead citrate, examined at 20000 and $40000 \mathrm{X}$ magnifications and photographed using a Zeiss 109 electron microscope.

Morphological parameters of skin mitochondria were analyzed using a computerized image analyzer (OPTIMAS $6.02)^{18}$. Thus, quantitative analysis comprised determination of mitochondrial axis length, area, perimeter, size and the presence or absence of crystolysis, edema and membrane integrity.

\section{Statistical analysis}

Data are expressed as means \pm 2 SEM. Comparisons between groups were calculated by Student's $t$-test for independent samples, and $\mathrm{p}<0.05$ was considered statistically significant. All statistics were carried out using SPSS software version 15.0 (SPSS, Inc. Chicago).

\section{RESULTS}

Clinical data of the studied population are shown in Table. The average age in ALS group was $43.8( \pm 11.71)$ and $46.25( \pm 13.25)$ years in the control group (p:ns). Observations of mitochondrial morphology in keratynocytes from SALS 
patients revealed important differences with healthy controls. Thus, the mitochondrial major axis length was significantly lower in SALS patients in comparison to the organelles from control keratynocytes (SALS: $0.358 \pm 0.150 \mu \mathrm{m}$; controls: $0.440 \pm 0.166 \mu \mathrm{m}$; mean \pm 2 SEM; $p<0.001$ ) (Fig 1A). Fig $1 \mathrm{~B}$ shows the comparison of mitochondrial area in the two groups obtained by image analysis. Mitochondrial area was also significantly reduced in SALS vS. control mitochondria (SALS: $0.076 \pm 0.061 \mu \mathrm{m}^{2}$; controls $0.105 \pm 0.072 \mu \mathrm{m}^{2}$; $\mathrm{p}<0.001)$. The same trend was found for the mitochondrial perimeter, which was decreased in SALS keratynocytes $(1.106 \pm 0.445 \mu \mathrm{m})$ compared with controls $(1.349 \pm 0.481 \mu \mathrm{m}$; $\mathrm{p}<0.0001$ ) (Fig 1C).

Typical microphotographs obtained by electron microscopy of keratynocyte ultrastructure are shown in Fig 2. Upper and lower microphotographs on the left hand side confirmed the decreased size of SALS mitochondria (asterisk, Fig 2A, C) as opposed to the organelles of control keratynocytes (Fig 2B, D). Whereas most mitochondria from controls showed the expected size, occasionally some smaller mitochondria were observed as well (Fig 2B; arrowhead).

Higher magnification photomicrographs (40000 X) allowed a further comparison of intramitochondrial ultrastructure (Fig 3). In this case, several mitochondria from SALS patients showed increased signs of crystolysis, which were totally absent in controls (arrow, Fig 3B). In addition, $4.46 \%$ of the total number of mitochondria obtained from the skin of SALS patients presented a disorganized ultrastructure, including disrupted cristae and loss of membrane integrity near the poles (Fig 4A, arrowhead). This abnormality was not observed in healthy controls (Fig 4B). In summary, electron microscopy observations of SALS skin mitochondria revealed that severe pathological changes, including decreased size, edematous matrix and damage of mitochondrial membranes, were specifically associated with the neurodegenerative condition.

\section{DISCUSSION}

The present investigation demonstrated pronounced morphological abnormalities in skin keratinocytes of SALS patients. Low power microscopy of skin biopsies in our series of patients showed mitochondria of small size, along with reductions in area and perimeter. In addition, high power microscopy evidenced damage to cristae, edema and altered membrane continuity. These findings are in consonance with mitochondrial abnormalities reported in the central nervous system of SALS patients and animal models of motor neuron degeneration ${ }^{8,10}$. Our present investigation suggests that changes taking place in skin mitochondria may reflect to some extent the mitochondrial abnormalities of the degenerating nervous system.
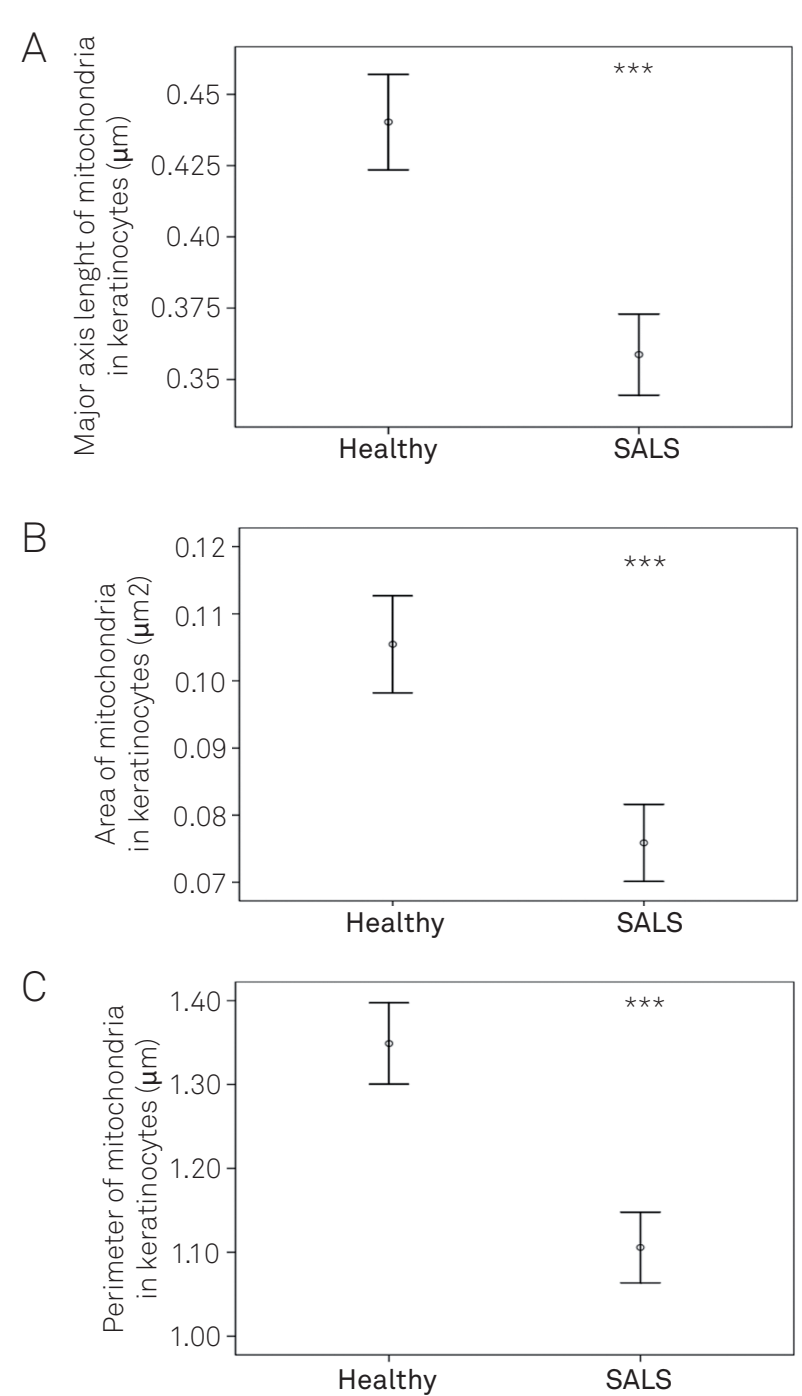

Fig 1. (A) Quantitation of the mitochondrial major axis length (mean \pm 2 SEM) in keratinocytes from healthy subjects (Healthy) and sporadic amyotrophic lateral sclerosis (SALS) patients. Statistical analysis demonstrated significant lower values in the mitochondrial major axis length in keratinocytes from SALS patients ( $* * * p<0.001$ vs. healthy controls). (B) Computarized analysis of the mitochondrial area (mean \pm 2 SEM) in keratinocytes from healthy subjects (Healthy) and SALS patients. A significant decrease in this parameter was demonstrated in keratinocytes from SALS patients ( $* * * p<0.001 \mathrm{vs}$. healthy controls). (C) Computerized image analysis of the mitochondrial perimeter. Mitochondrial perimeter was significantly decreased (SALS) respect of healthy subjects $(* * * p<0.0001)$.

Table. Demographic and clinical characteristics of sporadic amyotrophic lateral sclerosis patients and controls.

\begin{tabular}{lcccc}
$\begin{array}{c}\text { ALS } \\
\text { Patients }\end{array}$ & Sex & Age & $\begin{array}{c}\text { ALS } \\
\text { type }\end{array}$ & $\begin{array}{c}\text { Time onset to } \\
\text { diagnosis (months) }\end{array}$ \\
\hline 1 & Male & 41 & Spinal & 14 \\
2 & Male & 46 & Spinal & 7 \\
3 & Male & 26 & Bulbar & 48 \\
4 & Fem. & 58 & Spinal & 7 \\
5 & Male & 48 & Spinal & 35 \\
Controls & & & & \\
6 & Male & 37 & & \\
7 & Fem. & 38 & & \\
8 & Male & 45 & & \\
9 & Fem. & 65 & & \\
\hline
\end{tabular}

ALS: amyotrophic lateral sclerosis. 

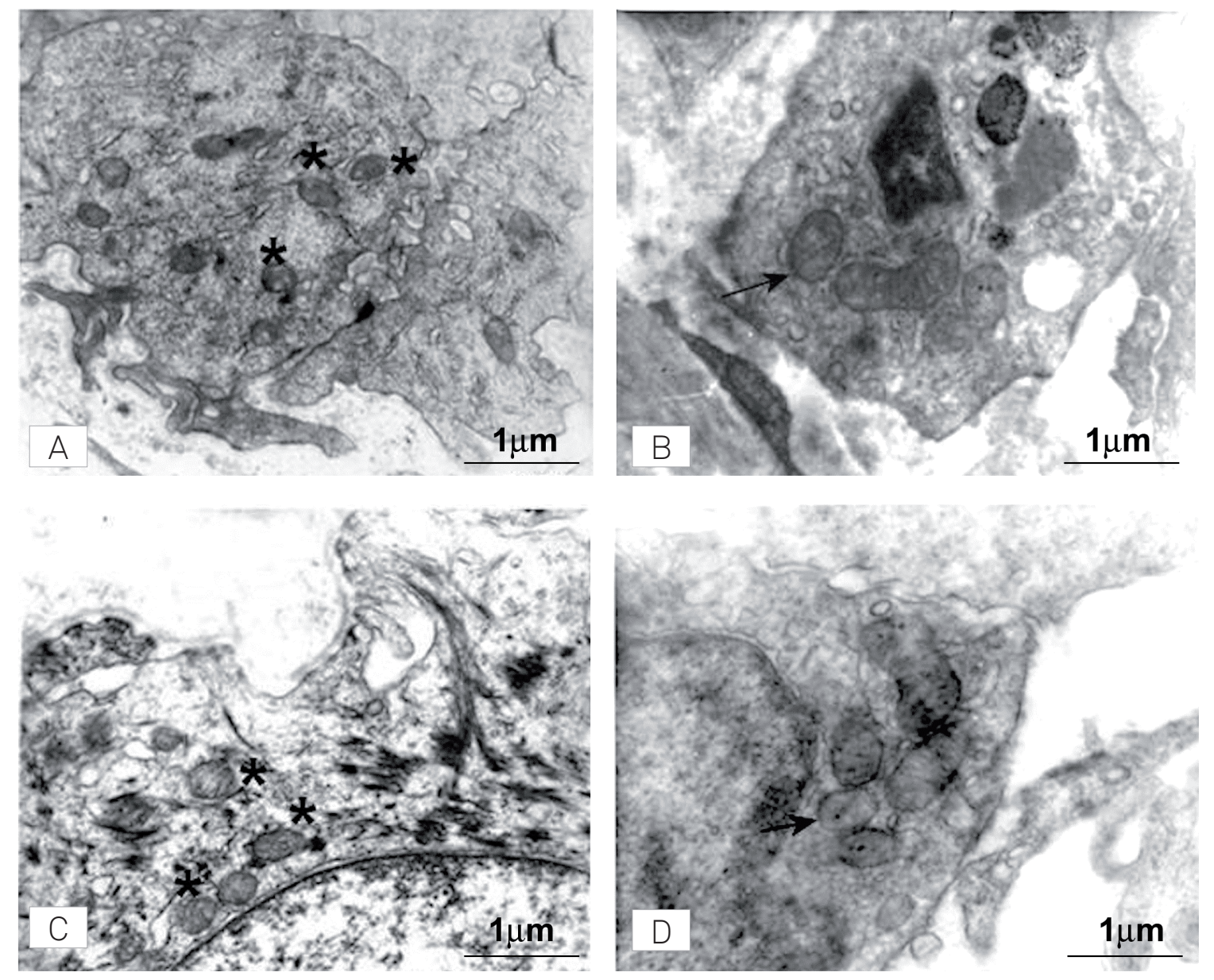

Fig 2. Electron microscope microphotographs in keratinocytes from control subjects and sporadic amyotrophic lateral sclerosis (SALS) patients. (A and C) SALS keratinocyte showing mitochondria of lower size (asterisk) than those found in healthy controls (B and D). Magnification: $20000 \mathrm{X}$.

Abnormal mitochondria is an important source of ROS, but also become damaged when handling of ROS is unbalanced $^{5}$. The involvement of increased oxidative stress involving mitochondria is a likely explanation, albeit probable incomplete, of SALS neurodegeneration. In this respect, increased mitochondrial volume in motor nerve terminals of SALS patients was first described by Siklós et al in $1996^{13}$. Other reports also found morphologic abnormalities of mitochondria in SALS patients, either in liver biopsy specimens ${ }^{11}$ or in axons, which show accumulation of mitochondria as well ${ }^{13}$. Interestingly, conglomerates of dark mitochondria at the presynaptic terminals of anterior spinal motor neurons were described by Sasaki and colleagues ${ }^{28}$, suggesting mitochondrial involvement in disabled synaptic contacts between lower motor neurons and their inputs. In addition, functional abnormalities of the mitochondria were described in the CNS, liver and muscle of SALS patients ${ }^{10,11,14}$. These changes suggest that the neurochemical basis for the observed morphological changes are widespread among different tissues and may consist in impaired mitochondrial bioenergetics, loss of membrane potential, reduced calcium buffering capacity and disrupted calcium homeostasis ${ }^{29}$.

In our investigations, we resorted to explore skin mitochondria, because the skin may be, as well, a target for the SALS disease's putative causes. Clinical signs of skin pathology described in the Introduction are accompanied by changes of the transactivation-responsive DNA-binding protein-43 (TDP-43), one of the major component of the ubiquitin-positive inclusions in SALS ${ }^{30}$. However, to date, no abnormalities had been described in the mitochondria of keratinocytes of these patients. Considering that mitochondria of liver, muscle and other tissues are affected, it became rational to assume that changes would also be seen in the mitochondria of keratinocytes, reinforcing the concept advanced by Siklós et al. ${ }^{13}$, that changes of mitochondrial area might be a marker of dysfunction.

Although mitochondrial function was not evaluated in our study, rupture of the mitochondrial membranes was one of the findings in the skin of SALS patients. It is known that the intrinsic apoptotic pathway originating in mitochondria is activated by ROS improperly handled by the cell's anti- 

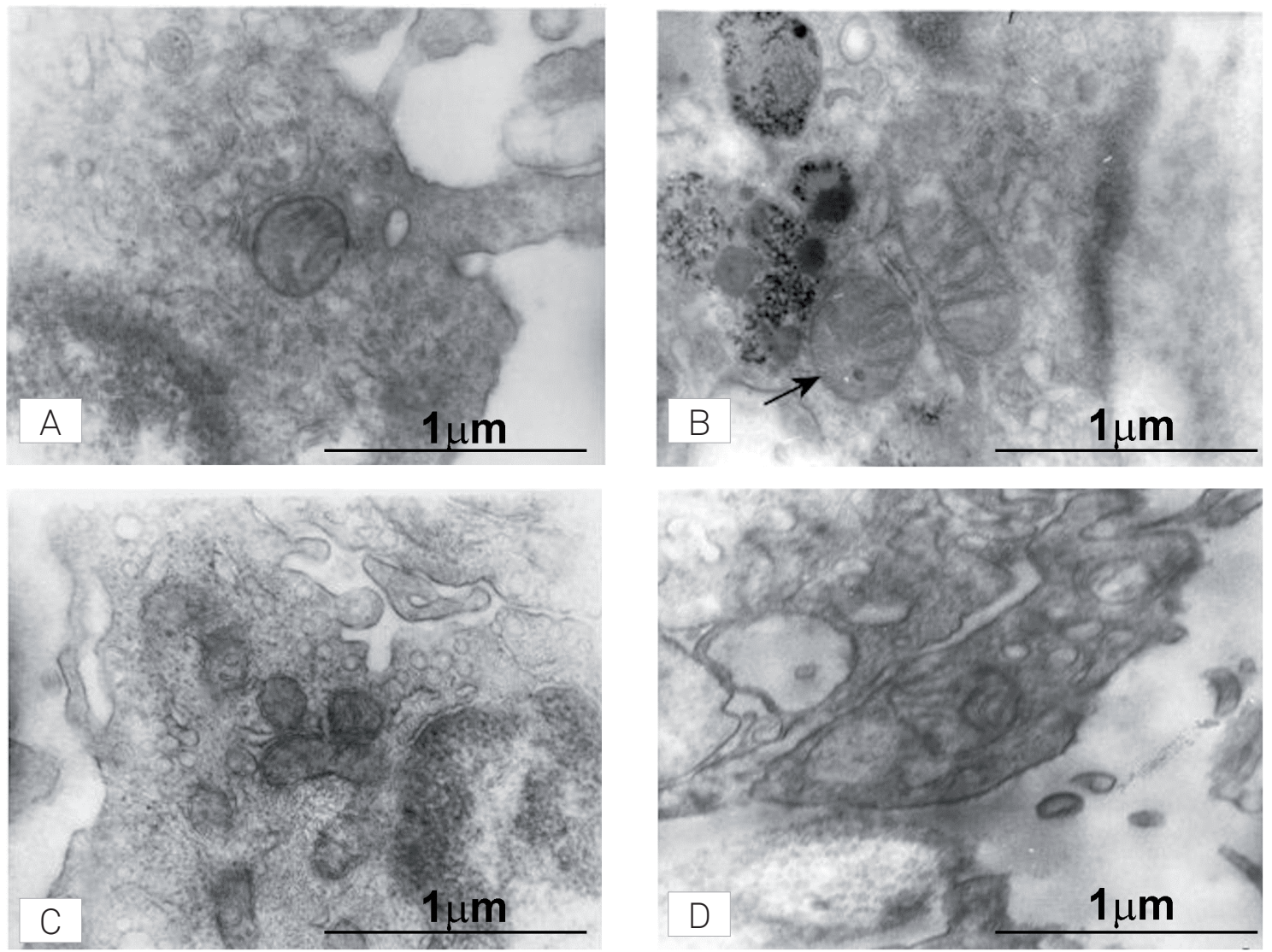

Fig 3. High-power electron microscopy photomicrographs showing smaller mitochondria in sporadic amyotrophic lateral sclerosis $(A, C)$ than in healthy controls (B, D). Magnification: $40000 \mathrm{X}$.
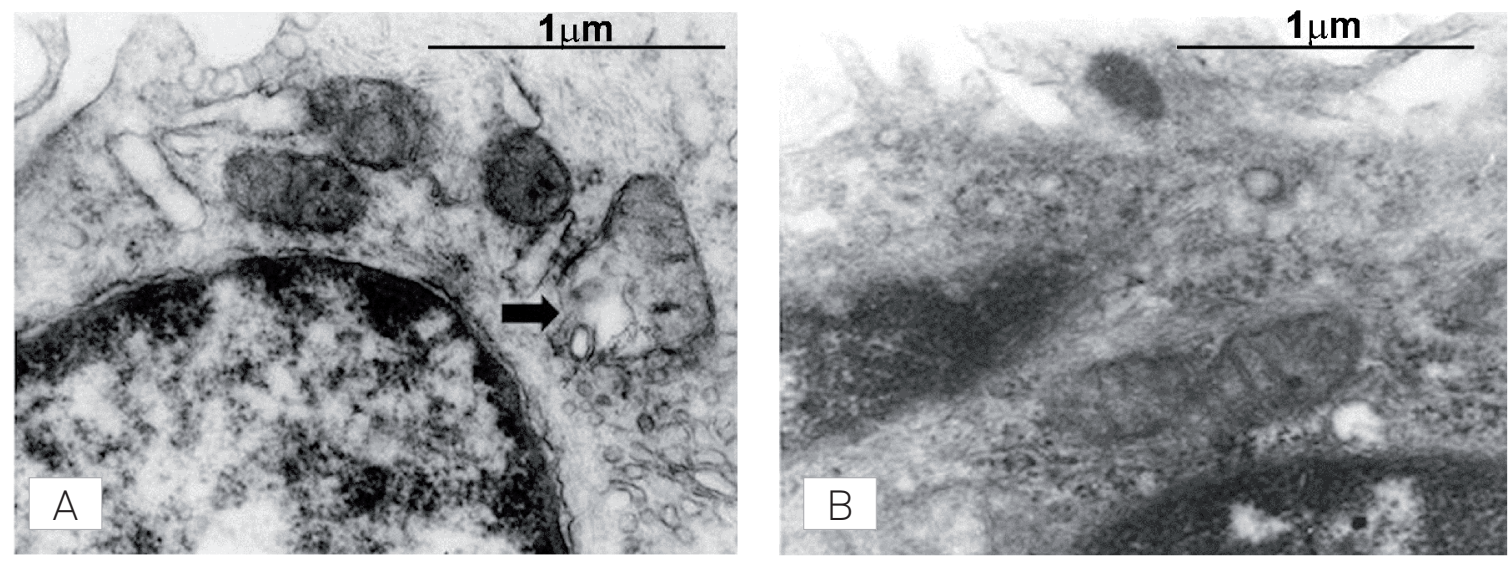

Fig 4. Electron microscopy microphotographs from keratinocytes obtained from sporadic amyotrophic lateral sclerosis (SALS) and healthy subjects. The arrow marks an abnormal mitochondrion in a keratinocyte obtained from a SALS patient, showing cristolysis and complete rupture of the outer membrane (A). Mitochondria from control subject (B). Magnification: 40000 X.

oxidant enzymatic machinery ${ }^{31}$. One of the typical morphological aspects of apoptosis is the breakdown of the external membrane, which causes the release of cytochrome $c$. The latter combines with the APAF molecule and caspase- 9 to form the apoptosome, leading to programmed cell death ${ }^{32}$.

From this point of view, the morphological changes of skin mitochondria demonstrated in this investigation may be the systemic expression of mitochondrial malfunction yielded by excessive ROS. It is presently unknown in tissues different from the CNS if local factors are responsible for higher levels of ROS or if they depend on an indiscriminate general state of oxidative stress ${ }^{33}$. Thus, there might be a systemic imbalance of ROS associated to this neurodegenerative disease that could explain ultrastructural lesions of skin mitochondria. In 
relation to this subject, increased serum levels of thiobarbituric acid reactive substances (TBARS) in SALS patients have been preliminary demonstrated in our laboratory (unpublished results).

In the present study, morphological changes found in SALS skin were restricted to mitochondrial size, area and membrane integrity. The altered parameters could result from the action of an environmental stressor whose intensity might produce a swift cell division in association to the breakdown of the mitochondrial membrane.

Thus, we suggest that mitochondrial damage may be a more widespread phenomenon than previously thought in
SALS, despite the fact that the CNS seems to be the main structure that clinically express the various semiological features characterizing the illness.

\section{ACKNOWLEDGEMENTS}

The laboratory assistance of Mariana López Ravasio (Instituto de Biología Celular y Neurociencias "Prof. E. de Robertis", School of Medicine, Buenos Aires University) is gratefully acknowledged. The authors would also like to thank the volunteers for their participation.

\section{References}

1. Dubrovsky A, Sica REP. Esclerosis lateral amiotrófica. Definición y criterios diagnósticos. In: Sica REP, Dubrovsky A (Eds). Esclerosis lateral amiotrófica y enfermedades relacionadas. Buenos Aires: Científica Interamericana; 2001.27-36.

2. Bonnefont-Rousselot D, Lacomblez L, Jaudon M, et al. Blood oxidative stress in amyotrophic lateral sclerosis. J Neurol Sci 2000;178:57-62.

3. Siciliano G, D’Avino C, Del Corona A, et al. Impaired oxidative metabolism and lipid peroxidation in exercising muscle from ALS patients. Amyotroph Lateral Scler Other Motor Neuron Disord 2002;3:57-62.

4. Shibata N, Nagai R, Uchida K, et al. Morphological evidence for lipid peroxidation and protein glycoxidation in spinal cords from sporadic amyotrophic lateral sclerosis patients. Brain Res 2001;917:97-104.

5. Wong PC, Pardo CA, Borchelt DR, et al. An adverse property of a familial ALS-linked SOD1 mutation causes motor neuron disease characterized by vacuolar degeneration of mitochondrial. Neuron 1995;14:1105-1116.

6. Afifi AK, Aleu FP, Goodgold J, Mackay B. Ultrastructure of atrophic muscle in amyotrophic lateral sclerosis. Neurology 1996;16:475-481.

7. Bowling AC, Schulz JB, Brown RH Jr, Beal MF. Superoxide dismutase activity, oxidative damage, and mitochondrial energy metabolism in familial and sporadic amyotrphic lateral sclerosis. J Neurochem 1993;61:2322-2325

8. Fujita K, Yamauchi M, Shibayama K, Ando M, Honda M, Nagata Y. Decreased cytochrome c oxidase activity but unchanged superoxide dismutase and glutathione peroxidase activities in the spinal cords of patients with amyotrophic lateral sclerosis. J Neurosci Res 1996;45:276-281.

9. Borthwick GM, Johnson MA, Ince PG, Shaw PJ, Turnbull DM. Mitochondrial enzyme activity in amyotrophic lateral sclerosis: implications for the role of mitochondria in neuronal cell death. Ann Neurol 1999;46:787-790.

10. Wiedemann FR, Manfredi G, Mawrin C, Beal MF, Schon EA. Mitochondrial DNA and respiratory chain function in spinal cords al ALS patients. J Neurochem 2002;80:616-625.

11. Nakano Y, Hirayama K, Terao K. Hepatic ultrastructural changes and liver dysfunction in amyotrophic lateral sclerosis. Arch Neurol 1987;44:103-104.

12. Curti D, Malaspina A, Facchetti G, et al. Amyotrophic lateral sclerosis: oxidative energy metabolism and calcium homeostasis in peripheral blood lymphocytes. Neurology 1996;47:1060-1064.

13. Siklós L, Engelhardt J, Harati Y, Smith RG, Joó F, Appel SH. Ultrastructural evidence for altered calcium in motor nerve terminals in amyotrophic lateral sclerosis. Ann Neurol 1996;39:203-216.
14. Wiedemann FR, Winkler K, Kuznetsov AV, et al. Impairment of mitochondrial function in skeletal muscle of patients with amyotrophic lateral sclerosis. J Neurol Sci1998;156:65-72.

15. Vielhaber S, Kunz D, Winkler K, et al. Mitochondrial DNA abnormalities in skeletal muscle of patients with sporadic amyotrophic lateral sclerosis. Brain 2000;123:1339-1348.

16. Dal Canto MC, Gurney ME. Development of central nervous systempathology in a murine transgenic model of human amyotrophic lateral sclerosis. Am J Pathol 1994;145:1271-1279.

17. Kong $\mathrm{J}, \mathrm{Xu}$ Z. Massive mitochondrial degeneration in motor neurons triggers the onset of amyotrophic lateral sclerosis in mice expressing a mutant SOD1.J Neurosci 1998;18:3241-3250.

18. Gonzalez Deniselle MC, López-Costa JJ, Saavedra JP, et al. Progesterone neuroprotection in the Wobbler mouse, a genetic model of spinal cord motor neuron disease. Neurobiol Dis 2002;11:457-468.

19. Lin MT, Beal MF. Mitochondrial dysfunction and oxidative stress in neurodegenerative diseases. Nature 2006;443:787-795.

20. Fullmer HM, Siedler HD, Krooth RS, Kurland LT. A cutaneous disorder of connective tissue in amyotrophic lateral sclerosis. A histochemical study. Neurology 1960;10:717-724.

21. Ono S, Toyokura Y, Mannen T, IshibashiY.Amyotrophic lateral sclerosis: histologic, histochemical, and ultrastructural abnormalities of skin. Neurology 1986;36:948-956.

22. Ono S, Yamauchi M. Amyotrophic lateral sclerosis: increased solubility of skin collagen. Neurology 1992;42:1535-1539.

23. Ono S, Nagao K, Yamauchi M. Amorphous material of the skin in amyotrophic lateral sclerosis: a morphologic and biochemical study. Neurology 1994;44:537-540.

24. Ono S, Imai T, Yamauchi M, Nagao K. Hyaluronic acid is increased in the skin and urine in patients with amyotrophic lateral sclerosis. J Neurol 1996;243:693-699.

25. Ono S, Imai T, Aso A, Yamano T, Shimizu N, Nagao K. Alterations of skin glycosaminoglycans in patients with ALS. Neurology 1998;51:399404.

26. Brooks BR. El Escorial World Federation of Neurology Criteria for the diagnosis of amyotrophic lateral sclerosis. Subcommittee on Motor Neuron Diseases/Amyotrophic Lateral Sclerosis of the World Federation of Neurology Research Group on Neuromuscular Diseases and the El Escorial "Clinical limits of amyotrophic lateral sclerosis" workshop contributors. J Neurol Sci 1994;124(Suppl): S96-S107.

27. Brooks B, Miller G, Swash M, Munsat TL. World Federation of Neurology Research Group on Motor Neuron Diseases. El Escorial revisited: revised criteria for the diagnosis of amyotrophic lateral sclerosis. Amyotroph Lateral Scler Other Motor Neuron Disord 2000;1:293-299. 
28. Sasaki S, Iwata M. Ultrastructural study of synapses in the anterior horn neurons of patients with amyotrophic lateral sclerosis. Neurosci Lett 1996;204:53-56.

29. Shi P, Gal J, Kwinter D, Liu X, Zhu H. Mitochondrial dysfunction in amyotrophic lateral sclerosis. Biochim Byophys Acta 2010;1802:45-51.

30. Suzuki M, Mikami H, Watanabe T, et al. Increased expression of TDP43 in the skin of amyotrophic lateral sclerosis. Acta Neurol Scand 2010;122:367-372.
31. Emerit J, Edeas M, Bricaire F. Neurodegenerative diseases and oxidative stress. Biomed Pharmacother 2004;58:39-46.

32. Li P, Nijhawan D, Budihardjo I, et al. Cytochrome $c$ and dATP-dependent formation of Apaf-1/caspase-9 complex initiates an apoptotic protease cascade. Cell 1997;91:479-489.

33. Fiszman ML, Borodinsky LN, Ricart KC, Sanz OP, Sica RE. Cu/Zn superoxide dismutase activity at different activity ages in sporadic amyotrophic lateral sclerosis. J Neurol Sci 1999;162:34-37. 